\title{
Radiation Chemistry of Overirradiated Aqueous Solutions of Hydrogen Cyanide and Ammonium Cyanide
}

\author{
Z.D. Draganić, I.G. Draganić, J.A. Azamar, S.I. Vujošević, M.D. Berber, and A. Negrón-Mendoza
}

Centro de Estudios Nucleares, UNAM, Cuidad Universitaria, Circuito Exterior, Delegación de Coyoacan, 04510-Mexico, D.F., Mexico

Summary. The radiolysis of aqueous solutions $\left(\mathrm{O}_{2}\right.$ free) of $\mathrm{HCN}$ and $\mathrm{NH}_{4} \mathrm{CN}$ was examined at very large doses of ${ }^{60} \mathrm{Co}$ gamma radiation (up to 230 $\mathrm{Mrad})$. In this dose range the cyanide initially present $(0.12 \mathrm{M})$ is decomposed and only its radiolytic products participate in the radiation-induced chemical process. It has been found that the weight of the dry residue containing the mixture of nonvolatile radiolytic products increases as doses increase up to $40 \mathrm{Mrad}$ (up to about $4 \mathrm{~g} / \mathrm{l}$ ), but with further dose increases remains practically unchanged $\left(\mathrm{NH}_{4} \mathrm{CN}\right)$ or decreases slightly (HCN). Carboxylic and amino acids are present in overirradiated samples. At increasing doses their concentrations decrease, with the exception of oxalic and malonic acids, which are continually produced and accumulate. This is also the case with the abundant $\mathrm{NH}_{3}$ and $\mathrm{CO}_{2}$, as well as with several other products that were generated at lower radiation-chemical yields. The molecular weights of the radiolytic products are up to 20,000 daltons throughout the dose range studied. Their amounts gradually change with increasing doses above 30 Mrad: The compounds with $\mathbf{M}_{w}$ between 2,000 and 6,000 daltons become more abundant, while the amounts of polymers with $\mathbf{M}_{w}$ between 6,000 and 20,000 decrease. The relevance of these findings for studies of chemical evolution is considered.

Key words: Cyanides - Aqueous solutions - Ionizing radiation - Radiolysis-Chemical evolution

\section{Introduction}

Hydrogen cyanide is an important precursor of many biomolecules in chemical processes using a variety of energy sources (Miller and Orgel 1974a; Fox and Dose 1977). One possible energy source is ionizing radiation (Draganić and Draganić 1980). The ra- diolysis of aqueous solutions of $\mathrm{HCN}$ and $\mathrm{NH}_{4} \mathrm{CN}$ has been studied quite intensively, both because the radiolytic products are of interest in chemical evolution studies and because of interest in the versatility of the carbon-nitrogen triple bond in irradiated aqueous solutions. Early work (Ogura 1967, 1968; Behar and Fessenden 1972; Ogura et al. 1972; Draganić et al. 1973, 1976a; Behar 1974; Büchler et al. 1976) was concerned with what are usually called the initial conditions: low (krad) radiation doses, at which little decomposition of solute occurs (a few percent at most) and the reaction mechanism is usually simple. Further studies (Draganić et al. 1976b, 1977a, 1980; Niketić et al. 1982, 1983; Negrón-Mendoza et al. 1983) were done at higher doses (up to $18 \mathrm{Mrad}$ ), at which substantial (up to 90\%) decomposition of cyanide took place and the accumulation of radiolytic products as well as their participation in the reaction mechanism was significant. More than 50 radiolytic products were identified, among them polymers with molecular weights of up to 20,000 daltons. These studies also supplied data on the earliest stages of radiolysis, the short-lived intermediates responsible for the observed changes, and the rate constants of various reactions.

At present we have a fairly complete picture of radiation-induced chemical processes in aqueous solutions of cyanide up to its decomposition, i.e., up to about $18 \mathrm{Mrad}$ for a $0.12-\mathrm{M}$ solution. These data are not sufficient, however, to predict phenomena in an overirradiated solution, i.e., after the irradiation of a cyanide system has been so prolonged that the radiation affects not only the cyanide ion but also the products of its decomposition.

The radiation chemistry of overirradiated solutions of cyanides is of interest for some evolutionary processes on the Precambrian Earth and in cometary nuclei. Hydrogen cyanide was very likely present in 
the early atmosphere and hydrosphere of our planet (Miller and Orgel 1974b), and is ubiquitous in extraterrestrial space (Hanel et al. 1981; Mann and Williams 1981; Tokunaga et al. 1981), particularly in cometary nuclei (Whipple 1976; Oppenheimer 1980; Delsemme 1982). Natural nuclear reactors were localized sources of ionizing energy on the Precambrian Earth and could produce absorbed doses larger than the $18 \mathrm{Mrad}$ that have been used in experiments with cyanide. Depending on the location of the reactor site and the efficiency of the flow of underground water, these doses could have been up to several tens of megarads (Draganić et al. 1983). Consideration of radiation-chemical aspects of cometary chemistry and dosimetry suggests that considerably larger doses, hundreds of megarads, may be involved in liquid cores of larger comets (Draganić et al. 1984). These doses are due to the energies of decay of various radionuclides that were present during accretion and imbedded in the cometary material. Of particular importance is ${ }^{26} \mathrm{Al}$ (Reeves 1979), the radiogenic heat of which could be sufficient to maintain liquid water cores in larger comets for several million years (Irvine et al. 1980; Wallis 1980).

This article concerns the effects of irradiation at absorbed doses larger, by up to about one order of magnitude, than those previously used for aqueous cyanide. It provides information on two aspects of prolonged irradiation: (1) the accumulation of small molecules produced radiolytically; and (2) the radiation resistance of larger radiolytic products, in particular those releasing carboxylic and amino acids. It is known that hydrogen cyanide in irradiated solutions acts not only as the precursor of some compounds, but also as their protector. By scavenging primary water radicals, it protects compounds in the solution from attack by them. We expected, therefore, that the gradual depletion of cyanide at increasing doses would have some consequences for the protection of radiolytic products in the overirradiated system. As this work shows, it does indeed, but the extent of survival of radiolytic compounds of interest to chemical evolution studies was found to be higher than was expected for the large doses used.

\section{Experimental}

Fresh solutions of $\mathrm{HCN}$ and $\mathrm{NH}_{4} \mathrm{CN}$ were prepared for each irradiation. The syringe technique was used for sample preparation and irradiation; details are given elsewhere (Draganić et al. 1976b, 1980).

The irradiation was carried out in the ${ }^{\circ} \mathrm{Co}$ unit at CENUNAM (Mexico) at a dose rate of $1.5 \mathrm{Mrad} / \mathrm{h}$; the temperature of the sample was up to $40^{\circ} \mathrm{C}$.

After irradiation the following measurements were made di-

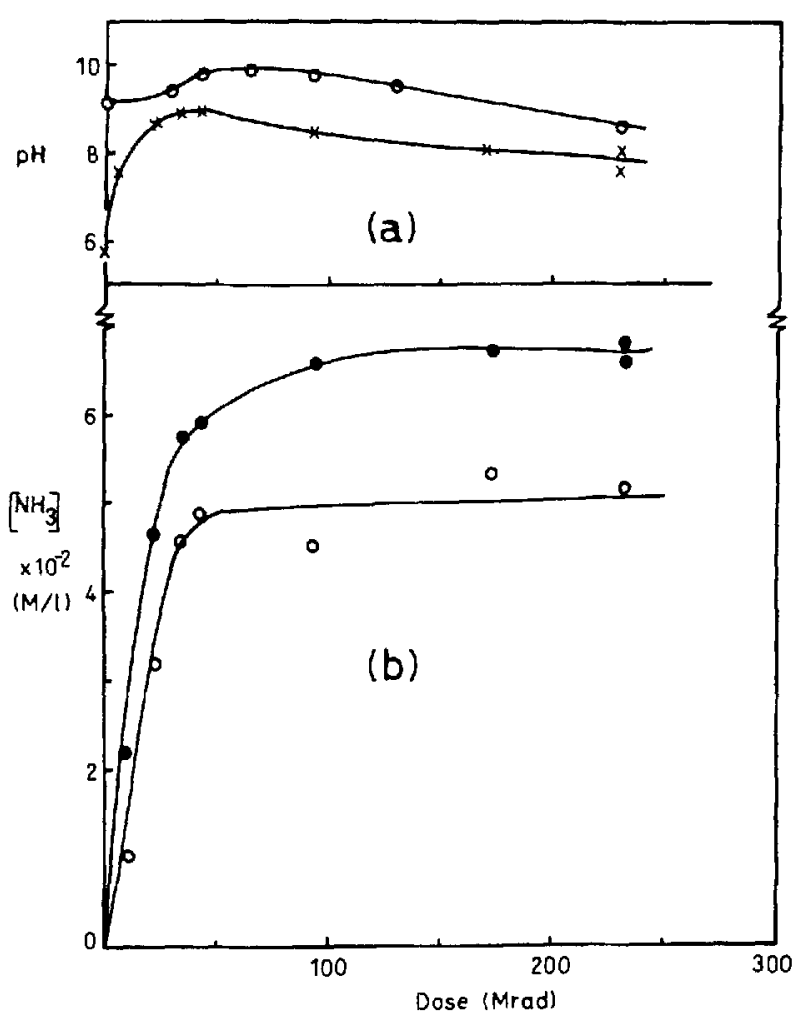

Fig. 1a, b. The influence of absorbed dose $\mathbf{a}$ on the $\mathrm{pH}$ of 0.12 $\mathrm{MHCN}(x)$ and $0.12 \mathrm{M} \mathrm{NH}_{4} \mathrm{CN}(\mathrm{O})$ solution; $b$ on the formation of ammonia in $\mathrm{HCN}$ solution, $\left[\mathrm{NH}_{3}\right]_{\text {free }}(\mathrm{O})$ and $\left[\mathrm{NH}_{3}\right]_{\mathrm{ot}}(\Theta)$, after microdiffusion for 3 and $24 \mathrm{~h}$, respectively

rectly on the irradiated sample: determination of $\mathrm{pH}$; determination of ammonia, using microdiffusion for its separation (Conway 1962) and Nessler reagent (Strenley and Averel 1969); and gas chromatographic determination of gases (Castillo-Rojas et al. 1985) and volatile compounds (Negrón-Mendoza et al. 1983).

The bulk of the irradiated solution $(100-400 \mathrm{ml})$ was evaporated at reduced pressure and $45^{\circ} \mathrm{C}$ to about $10 \mathrm{ml}$ and the concentrate was transferred to a freeze-drier and lyophilized. After lyophilization the dry residue was weighed and used for further analyses: the biuret test (Ellman 1962), infrared spectra, determination of carboxylic acids after hydrolysis and esterification (Negron-Mendoza et al. 1983), and search for amino acids upon acid hydrolysis (Draganić et al. 1980; Niketić et al. 1983). Molecular weight estimation was done on a $1 \times 11.5 \mathrm{~cm}$ Bio-gel P-10 column using $4 \mathrm{M}$ urea solution for elution (Niketic et al. 1983).

If not otherwise stated, the techniques used were the same as described previously (Draganić et al. 1976b, 1980).

\section{Results and Discussion}

\section{General}

After irradiation the solutions are transparent and yellowish in color. The color intensity increases with dose for doses up to about $50 \mathrm{Mrad}$; with further dose increases it becomes gradually weaker, so that at about 230 Mrad the solution is colorless.

Figure 1 summarizes the data on $\mathrm{pH}$ and am- 


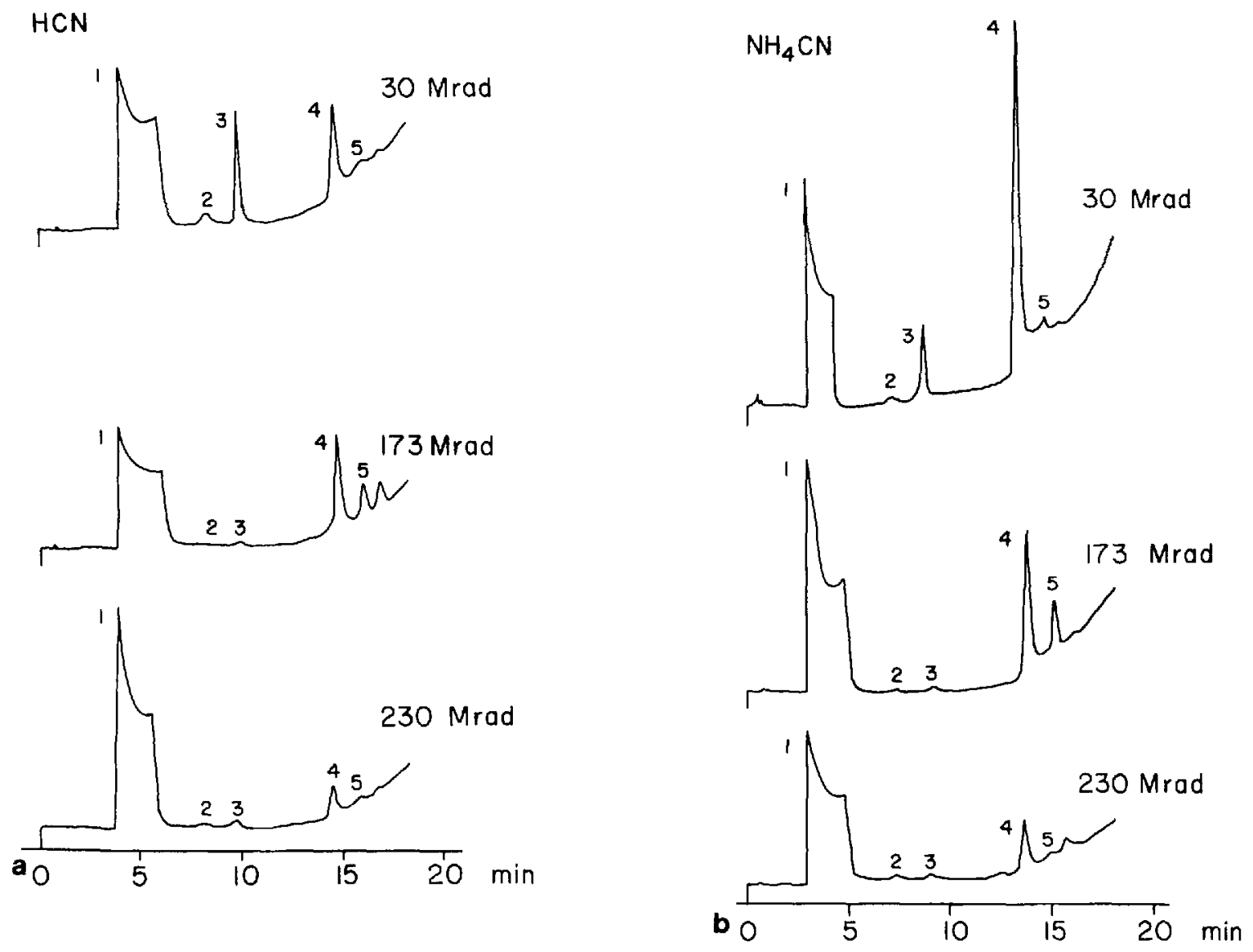

Fig. 2. Volatile radiolytic products in irradiated aqueous cyanides, measured by gas chromatography after direct injection of an aliquot of irradiated sample onto a column packed with Chromosorb 102 (80/100 mesh). Legend: (1) $\mathrm{H}_{2} \mathrm{O},(2) \mathrm{HCHO},(3) \mathrm{CH}_{3} \mathrm{CHO}_{\text {, }}$ (4) unknown, (5) $\mathrm{CH}_{3} \mathrm{COCHO}$ and/or $\mathrm{CH}_{3} \mathrm{COCH}_{3}$

monia content of the irradiated solutions. It shows that the buildup of ammonia in HCN solutions can roughly account for the increase in $\mathrm{pH}$; this is also the case with $\mathrm{NH}_{4} \mathrm{CN}$ at doses above $30 \mathrm{Mrad}$, at which the cyanide ion is decomposed. The difference between $\left[\mathrm{NH}_{3}\right]_{\text {tot }}$ and $\left[\mathrm{NH}_{3}\right]_{\text {free }}$ in HCN corresponds to the concentration of primary amides, which are radiolytically produced and release ammonia under prolonged microdiffusion (Fig. Ib).

The analyses of gases show the presence of $\mathrm{CO}_{2}$, $\mathrm{H}_{2}, \mathrm{CO}$, and $\mathrm{CH}_{4}$. The concentration of $\mathrm{CO}_{2}$ increases with dose and was found to be $1.8 \times 10^{-2}$ and $2.5 \times 10^{-2} \mathrm{M}$ for 50- and 100-Mrad doses, respectively; these values were the same to within $15 \%$ for $\mathrm{HCN}$ and $\mathrm{NH}_{4} \mathrm{CN}$ samples. This increase with dose contributes to bicarbonate formation and to the $\mathrm{pH}$ decrease. Molecular hydrogen accumulates with $\mathrm{G}\left(\mathrm{H}_{2}\right) \approx 0.4$, suggesting that its origin is due to water decomposition only. The concentrations of $\mathrm{CO}$ and $\mathrm{CH}_{4}$ increase slowly with dose, and at 50 Mrad were estimated to be about $10^{-5}$ and $10^{-6} \mathrm{M}$, respectively.

Volatile radiolytic products, mainly aldehydes, are found even at the largest doses (Fig. 2). Their total concentration is low, about $10^{-5} \mathrm{M}$ in $\mathrm{HCN}$ at a 10-Mrad dose (Negrón-Mendoza et al. 1983), and decreases to $10^{-6} \mathrm{M}$ at larger doses; the concentrations in $\mathrm{NH}_{4} \mathrm{CN}$ samples are only two to three times higher.

\section{Dry Residue}

The dry residue contains the mixture of nonvolatile radiolytic products and was of primary interest for the present work. On lyophilization of the liquid sample the residue appears as a brownish powder, but it becomes dark brown and oily after standing in air for only a few minutes. Its weight does not change with storage time. The residue remains oily and brown even upon repeated lyophilization, suggesting that the changes due to oxygen and moisture in the air are irreversible.

The amount of dry residue depends on the absorbed dose, as shown in Fig. 3. It should be noted that although its weight does not change significantly at doses above $40-50 \mathrm{Mrad}$, its physical properties 




Fig. 3. The influence of absorbed dose on the formation of dry residue in $0.12 \mathrm{M} \mathrm{HCN}(x)$ and $0.12 \mathrm{M} \mathrm{NH}_{4} \mathrm{CN}(0)$

do change: At increasing doses the dry residue becomes less colored and oily; it is a grayish powder at $230 \mathrm{Mrad}$ for both $\mathrm{HCN}$ and $\mathrm{NH}_{4} \mathrm{CN}$ samples. There are also some chemical changes in the composition of the dry residue, as shown by various chemical analyses of samples that received different doses of radiation.

The large amount of dry residue $(\sim 4 \mathrm{~g} / \mathrm{l})$ after a 40-Mrad dose is also worth noting. A comparison with the masses of cyanides initially present in $0.12-\mathrm{M}$ solutions (3.24 and $5.28 \mathrm{~g} / 1$ for $\mathrm{HCN}$ and $\mathrm{NH}_{4} \mathrm{CN}$, respectively) suggests that water makes an important contribution to the buildup of compounds in the dry residue, through hydrolyses and additions of primary water radicals to the carbonnitrogen triple bond.

\section{Biuret Test}

The biuret test, routinely used in protein chemistry for determination of peptide bonds, is also helpful in studies of abiotically produced materials if some precautions are taken in the interpretation of experimental results. A negative biuret test certainly means that peptide-bonded materials are absent, as was the case for oligomers produced by anionic processes in alkaline $\mathrm{NH}_{4} \mathrm{CN}$ (Ferris et al. 1981). A positive test, however, does not necessarily mean that absorbance is a direct measure of peptide bonds. For a reliable evaluation, the amount of amino acids released on acid hydrolysis and their origins have to be considered also, as well as the enzymatic digestion (Niketić et al. 1982).

Figure 4 summarizes the biuret test data: characteristic absorption spectra at different doses (Fig.

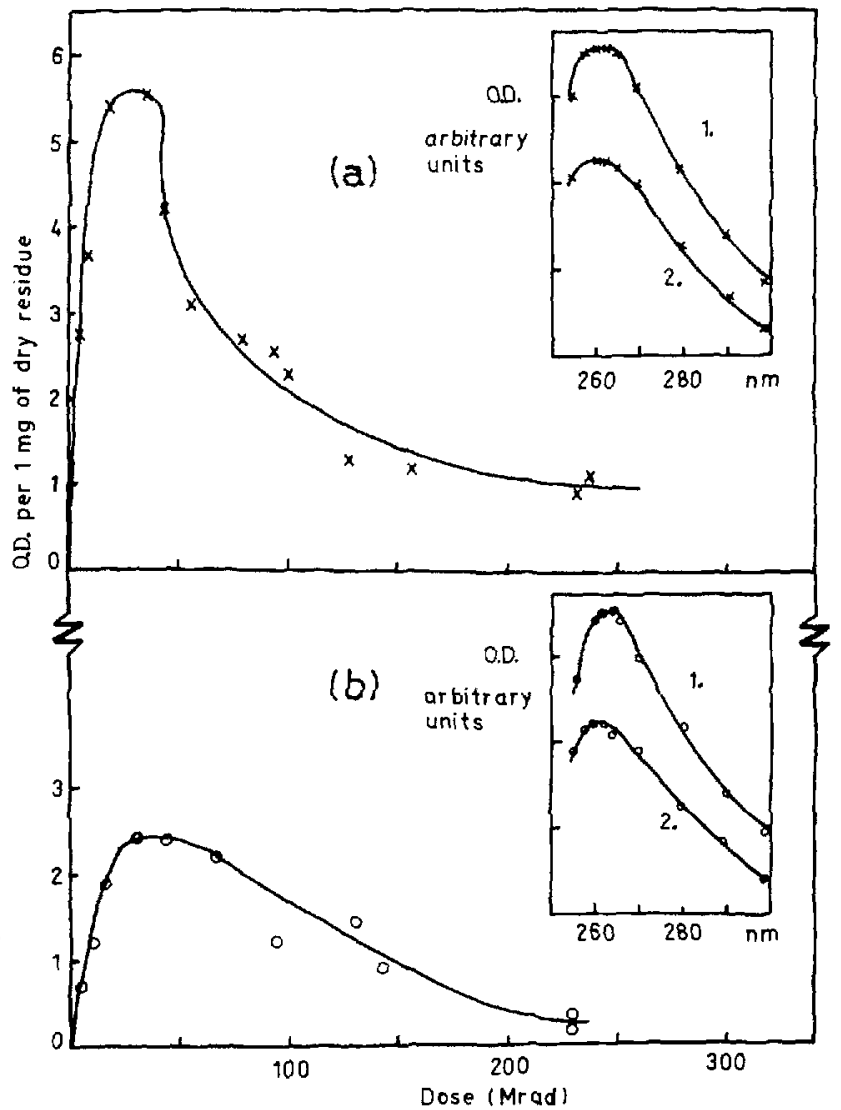

Fig. 4a, b. Biuret test in irradiated aqueous cyanides: $0.12 \mathrm{M}$ HCN and b $0.12 \mathrm{M} \mathrm{NH}_{4} \mathrm{CN}$. The data for doses up to $30 \mathrm{Mrad}$ are taken from Draganić et al. (1976b, 1977a). The insets present absorption spectra of samples that received different radiation doses: 43.2 Mrad (1) and $230 \mathrm{Mrad}$ (2)

4 , insets) and the dependence of absorbance on the dose absorbed. A comparison with amino acid data (Fig. 5) suggests that the absorbances of the biuret complex are much stronger than would be expected from the amino acid contents (molar absorptivity of the peptide bond in the biuret test was taken to be $800 \mathrm{M}^{-1}$; Draganic et al. 1980). Apart from the peptidic material, two oligomers that are already formed at low doses and were considered earlier (Draganić et al. 1980; Niketić 1983; Niketić et al. 1983) are among the radiolytic products contributing to the formation of the absorbing complex: oligoamide and urea-aldehyde.

The decrease in absorbances after about $40 \mathrm{Mrad}$ points to the disappearance of some of the constituents of the mixture of products in the dry residue. Their degradation occurs through reactions with primary water radicals, which become more efficient at larger doses with the depletion of cyanide. This is supported by increased formation of $\mathrm{CO}_{2}$ and $\mathrm{NH}_{3}$. The disappearance could also be due partly to dimerizations and the formation of larger molecules. 


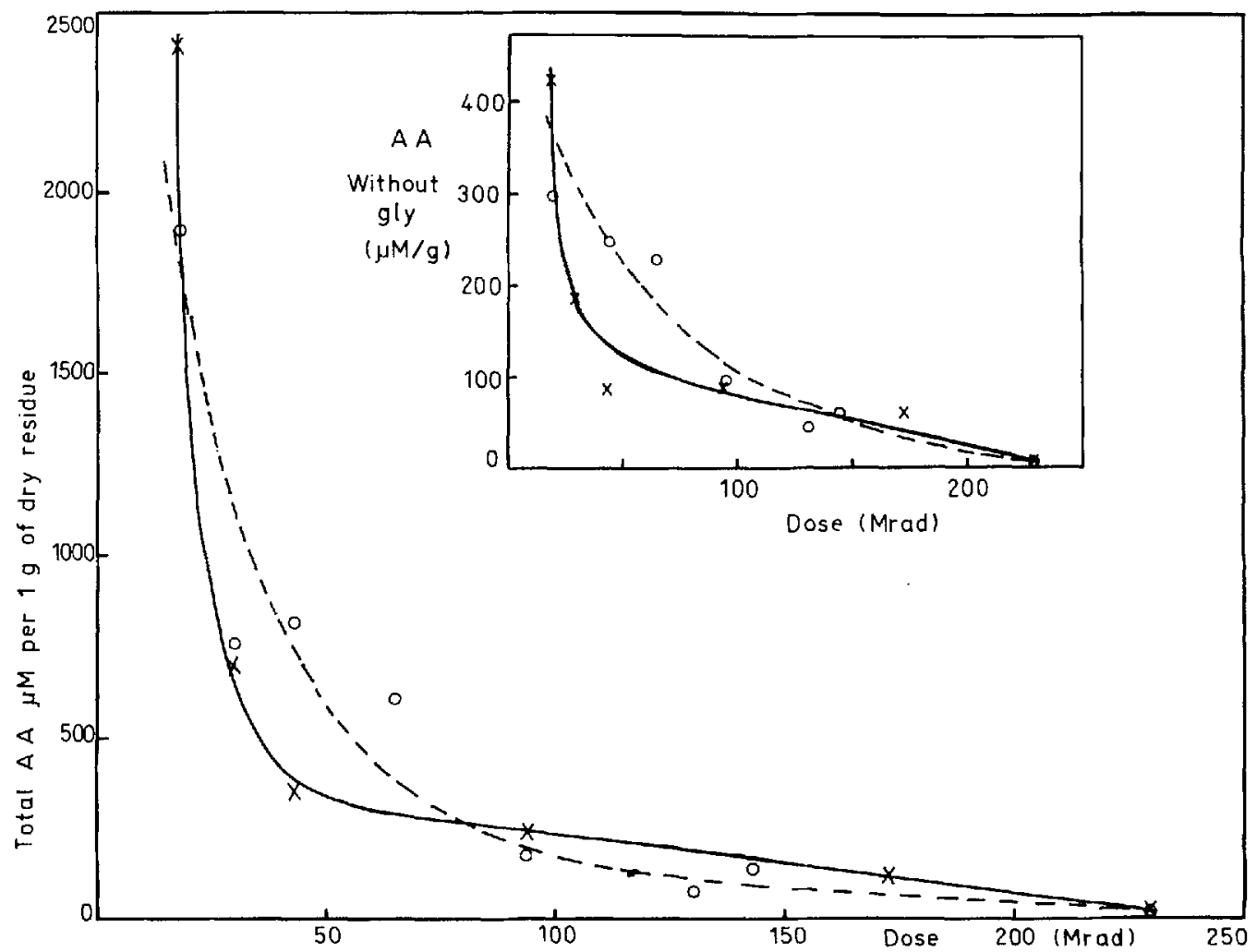

Fig. 5. Amino acid contents of hydrolysates of dry residues from irradiated aqueous solutions of $0.12 \mathrm{M} \mathrm{HCN}(\times)$ and $0.12 \mathrm{M}$ $\mathrm{NH}_{4} \mathrm{CN}(\mathrm{O})$. The data for the 18-Mrad dose are taken from Draganić et al. (1976b, 1977a). The inset shows data for total amino acids without glycine

\section{Amino Acids}

There are no free amino acids in the irradiated samples; the reported data concern the hydrolysates obtained by procedures routinely used in protein chemistry.

The dosage curve for the total amino acid content (Fig. 5) shows that they accumulate considerably (making up about $20 \%$ of the dry residue mass at $18 \mathrm{Mrad}$ ) while the cyanide ion is still present in the solution. Their formation stops and their concentration starts to decrease gradually after its depletion. However, they are still present to a significant degree at larger doses, since the peptide-bonded material is most likely incorporated in various oligomers that protect the segment containing the peptide backbone.

A comparison of the data in Fig. 5 shows that glycine is by far the most abundant amino acid. It originates not only from peptidic material, but also in the hydrolyses of certain carbamyl-glycine radiolytic products that are known to represent at least about $11 \%$ of the mass of dry residue: $\mathrm{N}$-carbamylglycinonitrile ( $\mathrm{HCN}, 6.4 \% ; \mathrm{NH}_{4} \mathrm{CN}, 3 \%$ ), $\mathrm{N}$-carbamylglycinamide (HCN, 3.1\%; Niketić et al. 1983), N-carbamylglycinoureid ( $\mathrm{HCN}, 1.1 \%)$, and bis(carbamyl-glycyno)oxotriazine $\left(\mathrm{NH}_{4} \mathrm{CN}, 8.3 \%\right.$;
Niketic 1983). The rapid decrease in total amino acid concentration with increasing dose at doses up to about $40 \mathrm{Mrad}$ is mainly due to loss of glycine from carbamyl-glycine derivatives. They decompose by reacting with primary water radicals faster than do the larger oligomeric products.

The amino acid analysis of hydrolysates of the dry residues showed the presence of amino acids that we saw at lower doses in previous work (Draganić et al. 1977b, 1980; Niketić et al. 1983): aspartic acid, threonine, serine, glutamic acid, alanine, $\beta$-alanine, and histidine. With the exception of serine and histidine, they were all also confirmed by gas chromatography-mass spectrometry (GC-MS). The trend of the dosage curve shown in the inset of Fig. 5 suggests that radiolytic products containing peptidic material and releasing amino acids are fairly resistant to radiation. This explains the presence of amino acids at doses (150-230 Mrad) that were larger by about one order of magnitude than the dose above which decomposition of cyanide and formation of peptidic radiolytic products have practically terminated.

\section{Urea and Methylamine}

Only some qualitative observations were made of urea and methylamine, and these were in agreement 

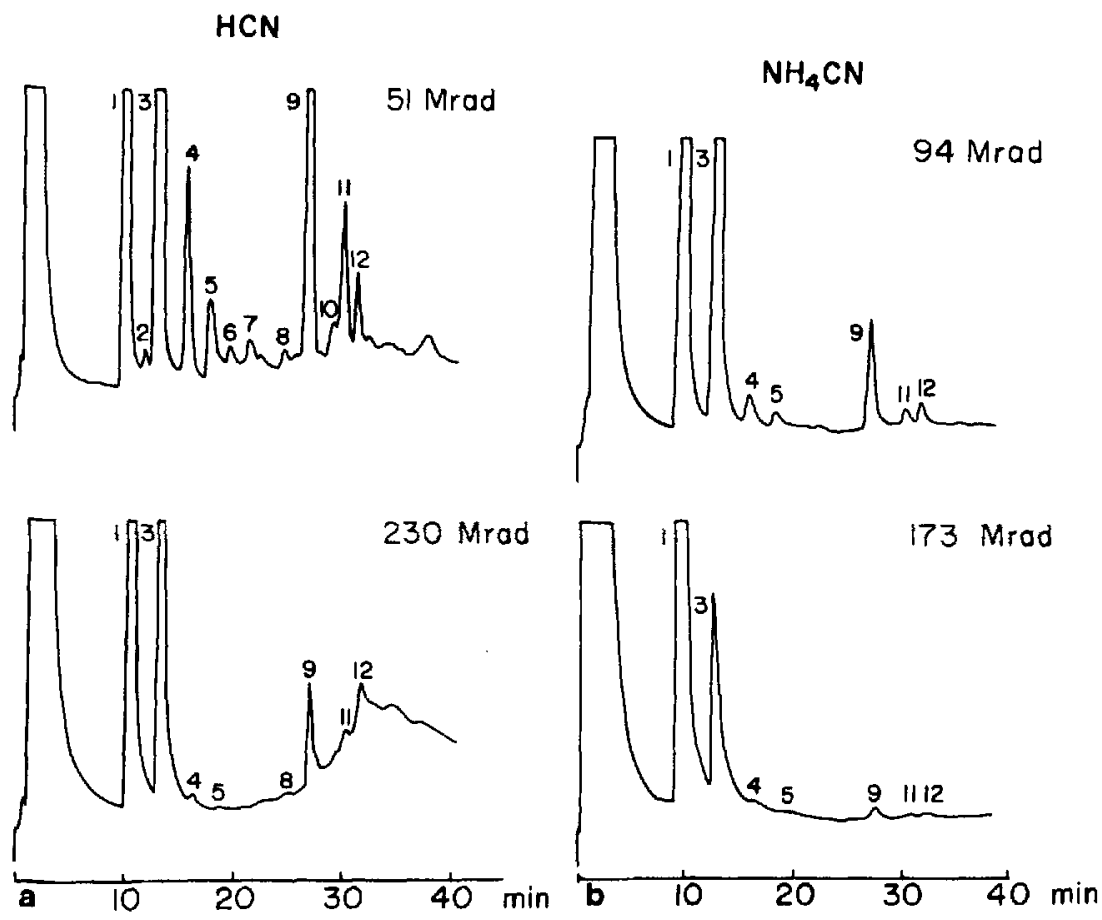

Fig. 6. Carboxylic acids in irradiated aqueous cyanides, as detected by gas chromatography after injection of methyl esters onto a column packed with Reoplex 400 (10\%) on Chromosorb W (a.w. DMCS, 80/100 mesh). Legend: (1) oxalic, (2) methyl malonic, (3) malonic, (4) succinic plus methyl succinic, (5) maleic, (6) glutaric, (7) unknown, (8) malic, (9) carboxysuccinic, (10) methyl tricarballylic, (11) tricarballylic, (12) unknown (dimethyl tricarballylic?)

with previous findings (Draganić et al. 1980; Niketić et al. 1983). The presence of free urea is significant even at the largest doses. On acid hydrolysis its concentration increases. Methylamine appears only in small amounts that decrease at larger doses.

\section{Carboxylic Acids}

Gas chromatography shows the presence of dicarboxylic and tricarboxylic acids (Fig. 6). They were found also at absorbed doses lower than $11 \mathrm{Mrad}$ in our earlier work (Negrón-Mendoza et al. 1983); the report of that work also gives more details about their identification and considers possible pathways for their formation. With the exception of 2-methyl tricarballylic acid, the identities of the carboxylic acids were confirmed by GC-MS; the samples were introduced as methyl esters on a Reoplex 400 chromatographic column, and the electron impact technique was used at $70 \mathrm{eV}$.

The total concentrations of carboxylic acids do not vary significantly from about $1.5 \times 10^{-4} \mathrm{M}$ for $\mathrm{HCN}$ (between 50 and $230 \mathrm{Mrad}$ ) and $3.5 \times 10^{-4}$ $\mathrm{M}$ for $\mathrm{NH}_{4} \mathrm{CN}$ (between 50 and $172 \mathrm{Mrad}$ ). There are however, significant differences in the behaviors of individual carboxylic acids. The amount of oxalic acid, which is the most abundant, gradually increases with absorbed dose in the dose range studied, i.e., after the depletion of cyanide ions. This shows that it originates mainly in reactions of primary water radicals with radiolytic products from decomposed cyanides, most likely $\mathrm{CO}_{2}$ which is present in the equilibrium with bicarbonate that accumulates in the solution. The amount of malonic acid also increases with dose. Concentrations of other carboxylic acids, such as tricarballylic and carboxysuccinic acid, decrease with increasing dose at doses above about $50 \mathrm{Mrad}$. The decrease is faster in $\mathrm{NH}_{4} \mathrm{CN}$ than in $\mathrm{HCN}$. This behavior, as well as their presence over the large dose range studied, suggests that they are produced as segments of oligomeric products in oligomerization reactions in the presence of cyanide, and that through these oligomers are more or less efficiently protected from the action of radiation.

\section{Infrared Spectra}

Essentially only those characteristic infrared bands that appeared at lower doses (Draganic et al. 1977c) are present in the samples studied. Their assignments are as follows (Jose 1969; Uno et al. 1969; Bellamy 1975, 1980): strong bands between 3400 and $3100 \mathrm{~cm}^{-1}$, the stretching mode of free and hydrogen-bonded $\mathrm{NH}$ and/or $\mathrm{NH}_{2}$; shoulders at 2960-2860 and 1340-1320 $\mathrm{cm}^{-1}$, the stretching and deformation frequencies of $\mathrm{CH}_{2}$ and $\mathrm{CH}$, respectively; strong absorption at $1670-1660 \mathrm{~cm}^{-1}$, the carbonyl (amide I); strong absorption at 1630-1620 $\mathrm{cm}^{-1}$ (amide II), the $\mathrm{NH}$ deformation mode and $\mathrm{C}$ $\mathrm{N}$ stretching mode; absorption near $1400 \mathrm{~cm}^{-1}$, the C-N stretching mode in primary amides; and the band near $1440 \mathrm{~cm}^{-1}$, the $\mathrm{C}-\mathrm{N}$ stretching mode and 
C-C skeletal vibrations in substituted ureas. The contribution of bicarbonate $\left(1490-1400 \mathrm{~cm}^{-1}\right)$ is negligible, as one would expect from its limited presence $(<3 \%)$ in the dry residue.

The infrared spectra suggest that primary amides, urea, and substituted ureas are among the constituents of the dry residues in the dose range studied. The increase in radiation dose leads only to some intensity increases in the bands at $1630-1620 \mathrm{~cm}^{-1}$ and near $1400 \mathrm{~cm}^{-1}$.

\section{Molecular Weights}

Oligomers and polymers are present throughout the dose range studied, with molecular weights up to 20,000 daltons. Their abundances vary with increasing dose at doses from 30 to 230 Mrad: The concentration of polymers with $\mathrm{M}_{\mathrm{w}}$ between 20,000 and 6000 daltons decreases, while that of radiolytic products with $M_{w}$ between 6000 and 2000 daltons increases. It has been found that the mass increase of the smaller polymers roughly accounts for the mass of the decomposed large radiolytic products. Linear polymers are known to undergo both random main-chain scission and crosslinking when exposed to ionizing radiation. In the present case, scission dominates. It leads to the formation of short-lived intermediates that react with the species present in the solution by forming radiolytic products with $\mathrm{M}_{\mathrm{w}}<6000$.

\section{Concluding Remarks}

1. The experimental findings suggest the presence of two main stages during prolonged radiolysis (up to $230 \mathrm{Mrad}$ ) of aqueous cyanides:

a) Absorbed doses up to $50 \mathrm{Mrad}$. The radiolytic decomposition of cyanide terminates at about $20 \mathrm{Mrad}$, as does the formation of most radiolytic products of $\mathrm{M}_{\mathrm{w}}$ 2000-20,000 daltons. At increasing doses up to $50 \mathrm{Mrad}$ their abundances as well as the total amino acid content (particularly the concentration of glycine), become lower. However, there is considerable accumulation of molecular hydrogen, ammonia, amides, carbon dioxide, and, to a lesser degree, carboxylic acids, methane, and carbon monoxide. The increase of the mass of nonvolatile radiolytic products (the dry residue) is particularly rapid.

b) Absorbed doses from 50 to $230 \mathrm{Mrad}$. That the concentrations of some products remain at steady state over this range is worth noting; these products are ammonia, carbon dioxide, amides, and trace amounts of aldehydes. This is also the case with the mass of the dry residue, which contains the mixture of nonvolatile radiolytic products (among them oligomers and polymers). Polymers of $\mathrm{M}_{\mathrm{w}} 6000-20,000$ daltons are present throughout the dose range studied, and their abundance decreases at larger doses. Oligomers of $M_{w}$ 2000-6000 daltons are also present in all samples, but their total amount gradually increases with dose increase. The observed increase accounts roughly for the disappearance of the polymers of $M_{w} 6000-20,000$ daltons.

2. Polycarboxylic and amino acids are found throughout the dose range studied. Their survival is very likely due to the fact that they are radiolytically produced as segments of oligomers and polymers, which act as protectors in the absence of cyanide during prolonged irradiation.

3. Radiation-induced chemical changes of a given compound in aqueous solution depend on various factors, of which the initial solute concentration and the dose range are among the most important. This has to be taken into account when considering the relevance of the present findings to phenomena on the primitive Earth or within a cometary nucleus. The concentration of cyanide in the primitive hydrosphere of our planet was very likely lower than that used in this work; such a concentration could have meant that the depletion of cyanide occurred at lower doses. However, the circulation of underground waters could have facilitated the renewal of cyanide as well as the removal of radiolytic products and their protection from further exposure to radiation. The possibility of renewal of cyanide is nil (and the absorbed doses could be considerably larger) in the liquid core of a cometary nucleus, but the initial concentration of cyanide is certainly considerably higher than the $0.12 \mathrm{M}$ that we used.

One also has to note that in the above-mentioned evolutionary processes, $\mathrm{HCN}$ was only one of the constituents of the irradiated system. The presence of other compounds leads to a complex reaction mechanism in which the cyanide can be more or less efficiently protected, since all constituents compete for radiation-produced water radicals $(\mathrm{H}, \mathrm{OH}$, $\mathrm{e}_{\mathrm{aq}}{ }^{-}$) that otherwise would attack the cyanide only.

Acknowledgment. The technical assistance of J.L. Torres is gratefully acknowledged. 


\section{References}

Behar D (1974) Pulse radiolysis study of aqueous hydrogen cyanide and cyanide solutions. J Phys Chem 78:2660-2663

Behar D, Fessenden RW (1972) An electron spin resonance investigation of the reactions in irradiated aqueous solutions of hydrogen cyanide and the cyanide ion. J Phys Chem 76: 3945-3950

Bellamy LJ (1975) The infra-red spectra of complex molecules. Chapman and Hall, London, pp 231-291

Bellamy LJ (1980) The infrared spectra of complex molecules, 2nd edn. Vol 2: Advances in infrared group frequencies. Chapman and Hall, London, pp 106-119, 154-186

Büchler H, Bühler RE, Cooper R (1976) Pulse radiolysis of aqueous cyanide solutions. Kinetics of the transient $\mathrm{OH}$ and $\mathrm{H}$ adducts and subsequent rearrangements. $J$ Phys Chem 80 : 1549-1553

Castillo-Rojas S, Negrón-Mendoza A, Draganić ZD, Draganić IG (1985) Radiat Phys Chem (in press)

Conway EJ (1962) Microdiffusion analysis. Crosby Lockwood and Son, London, pp 7-12

Delsemme AH (1982) Chemical composition of cometary nuclei. In: Wilkening LL (ed) Comets. The University of Arizona Press, Tucson, Arizona, pp 85-130

Draganić IG, Draganic ZD (1980) Radiation-chemical aspects of chemical evolution and radiation chemistry of simple cyano compounds. Radiat Phys Chem 15:195-201

Draganić I, Draganić Z, Petković LI, Nikolić A (1973) The radiation chemistry of aqueous solutions of simple $R C N$ compounds. J Am Chem Soc 95:7193-7199

Draganić IG, Draganić ZD, Marković VM (1976a) The pulse radiolysis of aqueous solutions of simple RCN compounds. Int J Radiat Phys Chem 8:339-342

Draganić ZD, Draganić IG, Borovičanin M (1976b) The radiation chemistry of aqueous solutions of hydrogen cyanide in the megarad dose range. Radiat Res 66:42-53

Draganić ZD, Draganić IG, Niketic V (1977a) The radiation chemistry of aqueous solutions of ammonium and sodium cyanides in the megarad dose range. Radiat Res 69:223-229

Draganić Z, Draganić I, Shimoyama A, Ponnamperuma C (1977b) Evidence for amino acids in hydrolysates of compounds formed by ionizing radiations: I. Aqueous solutions of $\mathrm{HCN}, \mathrm{NH}_{4} \mathrm{CN}$ and $\mathrm{NaCN}$. Orig Life 8:377-382

Draganić IG, Draganić ZD, Jovanović S, Ribnikar SV (1977c) Infrared spectral characterization of peptidic material produced by ionizing radiation in aqueous cyanides. $J$ Mol Evol 10:103-109

Draganić ZD, Niketić V, Jovanović S, Draganić IG (1980) The radiolysis of aqueous ammonium cyanide: compounds of interest to chemical evolution studies. J Mol Evol 15:239-260

Draganic IG, Draganić ZD, Altiparmakov D (1983) Natural nuclear reactors and ionizing radiation in the Precambrian. Precambrian Res 20:283-298

Draganić IG, Draganić ZD, Vujoševic SI (1984) Some radiation-chemical aspects of chemistry in cometary nuclei. Icarus 60:464-475

Ellman GL (1962) The biuret reaction: changes in the ultraviolet absorption spectra and its application to the determination of peptide bonds. Anal Biochem 3:40-48

Ferris JP, Edelson EH, Auyeung JM, Yoshi PC (1981) Structural studies of $\mathrm{HCN}$ oligomers. J Mol Evol 17:69-77
Fox SW, Dose K (1977) Molecular evolution and the origin of life. Marcel Dekker, New York, pp 138-141, 182-185

Hanel R, Conrath B, Flasar FM, Kunde V, Maguire W, Pearl J, Pirraglia J, Samuelson R, Herath L, Allison M, Kruikshank D, Gautier D, Girasch P, Horn L, Koppany R, Ponnamperuma C (1981) Infrared observations of the Saturnian system from Voyager 1. Science 212:192-200

Irvine WM, Leschine SB, Schloerb FP (1980) Thermal history, chemical composition and relationship of comets to the origin of life. Nature 283:748-749

Jose CI (1969) Infrared spectra of substituted ureas, I. Alkyl ureas. Spectrochim Acta 25A:111-118

Mann APC, Williams DA (1981) A list of interstellar molecules. Nature 283:721-725

Miller SL, Orgel LE (1974a, b) The origins of life on the Earth. Prentice-Hall, Englewood Cliffs, New Jersey, (a) pp 83-117, (b) pp 60-61

Negrón-Mendoza A, Draganić ZD, Navarro-González R, Draganić IG (1983) Aldehydes, ketones, and carboxylic acids formed radiolytically in aqueous solutions of cyanides and simple nitriles. Radiat Res 95:248-261

Niketic V (1983) Compounds of interest in prebiotic evolution studies obtained from the radiolysis of cyanides. Ph.D. thesis, University of Beograd, Yugoslavia

Niketić V, Draganić Z, Nešković S, Draganić I (1982) Enzymatic characterization of peptidic materials isolated from aqueous solutions of ammonium cyanide ( $\mathrm{pH} 9$ ) and hydrocyanic acid ( $\mathrm{pH} \mathrm{6)}$ exposed to ionizing radiation. J Mol Evol 18:130-136

Niketić V, Draganić ZD, Nešković S, Jovanović S, Draganic IG (1983) Radiolysis of aqueous solutions of hydrogen cyanide (pH 6): compounds of interest in chemical evolution studies. J Mol Evol 19:184-191

Ogura H (1967) Radiolysis of hydrogen cyanide in aqueous system. Part 1. Estimation of radiolytic yield of hydrogen cyanide and product investigation. J Radiat Res (Jpn) 8: 93-99

Ogura H (1968) Radiolysis of hydrogen cyanide in an aqueous system. II. Effects of additives and reaction mechanism. Bull Chem Soc (Jpn) 41:2871-2876

Ogura H, Fujimura T, Murozono S, Hirano K, Kondo M (1972) Radiolysis of hydrogen cyanide in an aqueous system. III. pH Dependence of radiolysis. J Nucl Sci Technol 9:339-343

Oppenheimer $M$ (1980) Chemical reactions and the nature of comets. Acc Chem Res 13:378-384

Reeves H (1979) Cosmochronology after Allende. Astrophys J 231:229-235

Strenley CA, Averel PR (eds) (1969) Analytical chemistry of nitrogen and its compounds. Part 1. John Wiley \& Sons, New York, pp 55-56

Tokunaga AT, Beck SC, Geballe TR, Lacy JH, Serabyn E (1981) The detection of HCN on Jupiter. Icarus 48:283-289

Uno T, Machida K, Hanai K, Saito Y (1969) Infrared spectra of acylureas and $\mathrm{NN}^{\prime}$-deuterated acylureas. Bull Chem Soc (Jpn) 42:619-624

Wallis MK (1980) Radiogenic melting of primordial comet interiors. Nature 284:431-433

Whipple FL (1976) Background of modern comet theory. Nature 263:15-19 